\title{
Development of SIMS (Simple Indigenous Metallic Stabilizer) for OPCAB
}

\author{
Murali P. Vettath, Kannan Arunachalam Venkatachalam, Nitin Gangadharan, \\ Madhu Ravisankar, Smera Koroth, Gopalakrishnan Raman
}

Meitra Hospital, Kozhikode, India

Email: murali.vettath@gmail.com

How to cite this paper: Vettath, M.P., Venkatachalam, K.A., Gangadharan, N., Ravisankar, M., Koroth, S. and Raman, G. (2019) Development of SIMS (Simple Indigenous Metallic Stabilizer) for OPCAB. World Journal of Cardiovascular Diseases, 9, 324-330.

https://doi.org/10.4236/wjcd.2019.95028

Received: April 11, 2019

Accepted: May 13, 2019

Published: May 16, 2019

Copyright $\odot 2019$ by author(s) and Scientific Research Publishing Inc. This work is licensed under the Creative Commons Attribution International License (CC BY 4.0).

http://creativecommons.org/licenses/by/4.0/

\begin{abstract}
Development of a simple, reusable stabilizer for beating heart surgery has been long overdue. Every time a disposable stabilizer is used and discarded, we add to the carbon footprint we leave behind. We had been working on developing such a stabilizer, and had finally come up with a simple indigenous (reusable) metallic stabilizer (SIMS). We have used it for over 600 consecutive off pump coronary artery bypass (OPCAB) with excellent results. The anatomy of the stabilizer is described here along with a comparison of this stabilizer with the commercially available one.
\end{abstract}

\section{Keywords \\ SIMS, OPCAB}

\section{Introduction}

OPCAB (off pump coronary artery bypass) has been the standard of care in a few centers around the world. We have been performing the same for over two decades. As one of the pioneers of this technique, we have fabricated, developed, innovated and re-engineered this technique to perform $\mathrm{OPCAB}$ in all patients needing CABG (coronary artery bypass grafting) [1]-[7]. We herewith present our recent innovation-A simple indigenous metallic stabilizer (SIMS) which we have used for the past three years. We have compared this with a similar number of OPCABs done using the commercially available stabilizer in the market.

Since the arrival of the first Octopus stabilizer in the market in the late nineties, we have been using them to perform OPCAB. In our country, these stabilizers have been reused by ethylene oxide sterilization, at an average of about ten times each so that the cost of surgery comes down.

As only $10 \%-15 \%$ of our population has medical insurance the cost of sur- 
gery is usually borne by the individual. Hence bypass surgeries becomes in affordable unless the cost is contained. It has been our endeavor to bring down the cost of cardiac surgery to the minimum, and the development of SIMS has definitely made it possible in a big way.

\section{Materials and Method}

Since 2015, we had started using our SIMS and by the end of 2018 we have used them in over 600 OPCABs. We have compared this with a similar 600 OPCABs performed using the commercially available Maquet stabilizers which we have been using for the last ten years. We have compared the ability of these two stabilizers in performing anastomosis in all the walls of the heart and to perform the grafts on all the coronary arteries we needed to graft. The comparative chart is provided in Table 1. We have noticed that both the stabilizers have been proficient in stabilizing in every region of the heart and once we started off with using SIMS, we have never ever had to go back on to these commercially available stabilizers ever again. The way to use this stabilizer is shown in the link provided in the last paragraph.

The interesting aspect is that we have used only two sets of SIMS stabilizers all through to perform these 600 OPCABs, without any need to replace them, and that its still being used. The only part that has to be changed every 5 to 10 cases was the stabilizer pods (Photo 1).

SIMS (simple indigenous metallic stabilizer)

The SIMS comes as a combo device (Photo 2), which is made of a sternal spreader with a railing on both sides (Photo 3 ) over which a vertical two inch metallic rod (Photo 4) could be fixed with a screw and its position could be moved according to the position of the coronary artery which needed to be bypassed. Over this metal rod, we have the stabilizer rod that is fixed at its base with another clamp, which in turn could be moved over the metal rod to which ever position we need. The stabilizer rod is in fact a curved metallic tube which houses another curved metal rod inside. The curved outer tube has a distal metal end that holds a housing in which the pod head (Photo 5) could be moved around. This housing has three slots which allows the pod to move in them until it is positioned. The proximal end of the outer tube has a screw which when screwed, would tighten the inner rod. The inner rod at its distal end is convex and this moves on the concave end of the interlocking rod in front of it. The interlocking rod is the crux of the stabilizer (sent for patenting). This is a half a centimetre piece of metal which is concave on both ends. The proximal concave end allows the metal rod to push it forward or distally, and the distal concave bit allows the head of the pod to rest on it. Hence when the pod is placed parallel to the coronary artery, we first tighten the rod in the intended position and the pod is positioned by tightening the screw at the proximal end. This screw in turn pushes the inner rod forward, which in turn pushes the interlocking rod which tighten and stabilizes the head of the pod in the desired position. This once positioned is so stable that it does not move at all. The pod has suckers like in the 
Table 1. Showing comparison of maquet stabilizer with SIMS.

\begin{tabular}{|c|c|c|c|}
\hline & Vessels & Maquet & SIMS \\
\hline \multicolumn{2}{|c|}{ Total Number of OPCAB Patients } & 600 & 600 \\
\hline \multicolumn{2}{|c|}{ Male } & 531 & 514 \\
\hline \multicolumn{2}{|c|}{ Female } & 69 & 86 \\
\hline \multirow{6}{*}{ LIMA } & LAD & 589 & 592 \\
\hline & SVG TO LAD & 2 & 0 \\
\hline & Diagonal & 3 & 3 \\
\hline & PDA & 0 & 1 \\
\hline & $\mathrm{OM}$ & 3 & 2 \\
\hline & RAMUS & 3 & 2 \\
\hline \multicolumn{2}{|c|}{ Total LIMA } & 600 & 600 \\
\hline \multirow{3}{*}{ RIMA } & LAD & 1 & 2 \\
\hline & $\mathrm{OM}$ & 0 & 5 \\
\hline & Distal CX & 1 & 4 \\
\hline \multirow[t]{6}{*}{ RADIAL } & PDA & 0 & 1 \\
\hline & $\mathrm{OM}$ & 0 & 1 \\
\hline & LAD & 2 & 0 \\
\hline & Diagonal & 185 & 210 \\
\hline & RI & 96 & 104 \\
\hline & $\mathrm{OM}$ & 370 & 422 \\
\hline \multirow[t]{5}{*}{ SVG } & Distal CX & 105 & 59 \\
\hline & Acute Marg & 14 & 4 \\
\hline & RCA & 17 & 15 \\
\hline & PDA & 289 & 301 \\
\hline & PLV & 59 & 90 \\
\hline \multicolumn{2}{|c|}{ Total SVG } & 1137 & 1205 \\
\hline \multicolumn{2}{|c|}{ CKD } & $68(11.3 \%)$ & $77(12.8 \%)$ \\
\hline \multicolumn{2}{|c|}{ IABP } & $25(4.16 \%)$ & $4(0.6 \%)$ \\
\hline \multicolumn{2}{|c|}{ Mortality } & $4(0.6 \%)$ & $2(0.3 \%)$ \\
\hline \multicolumn{2}{|c|}{ Post OP Ventilation HRS (Average) } & 11,364 (19.34 HRS) & 11,246 (18.14 HRS) \\
\hline \multicolumn{4}{|c|}{ Costing } \\
\hline \multicolumn{2}{|c|}{ Purchased Quantity (Cost for 1) } & 37 (@1000usd per piece) & 2 SET-with 20 PODS \\
\hline \multicolumn{2}{|c|}{ Total Cost for Stabilizer } & USD-37,000/- & USD-4000/- \\
\hline \multicolumn{2}{|c|}{ Total Cost For 2 Spreader } & USD -11,500/- & Comes with stabilizer \\
\hline \multicolumn{2}{|c|}{ Grand Total } & USD-48,500/- & USD-4000/- \\
\hline \multicolumn{4}{|c|}{ IN per Centage } \\
\hline \multicolumn{2}{|c|}{ MAQUET } & \multicolumn{2}{|c|}{ SIMS } \\
\hline Male & $88.50 \%$ & Male & $85.66 \%$ \\
\hline Female & $11.50 \%$ & Female & $14.34 \%$ \\
\hline CKD & $11.33 \%$ & CKD & $12.83 \%$ \\
\hline Conversion & $0.00 \%$ & Conversion & $0.00 \%$ \\
\hline IABP & $4.16 \%$ & IABP & $0.60 \%$ \\
\hline Average No. of Grafts & 2.89 & No. of Grafts & 3.0 \\
\hline Mortality & $0.60 \%$ & Mortality & $0.30 \%$ \\
\hline
\end{tabular}




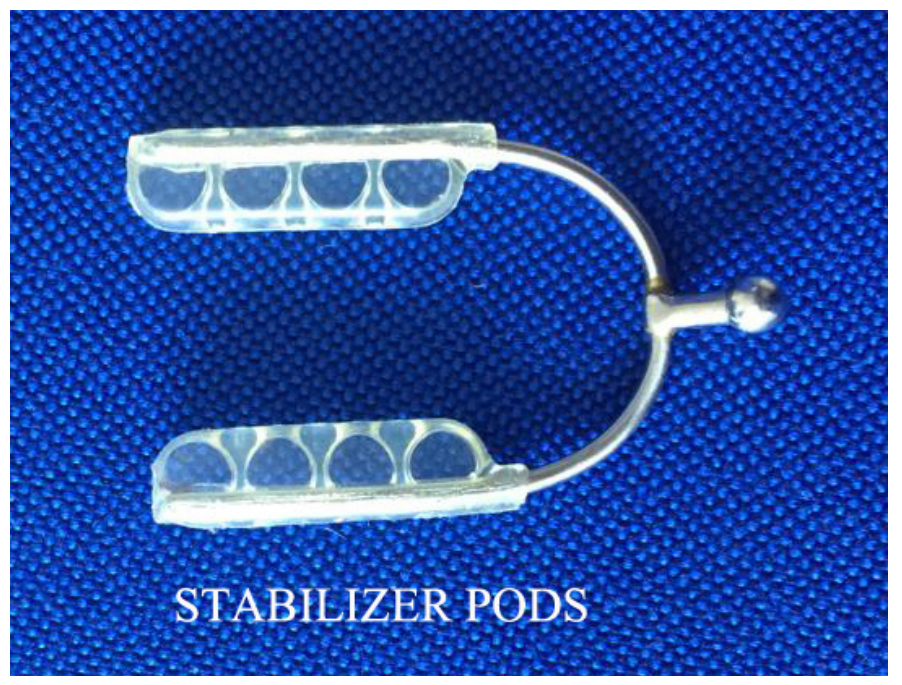

Photo 1. SIMS (simple indigenous metallic stabilizer).

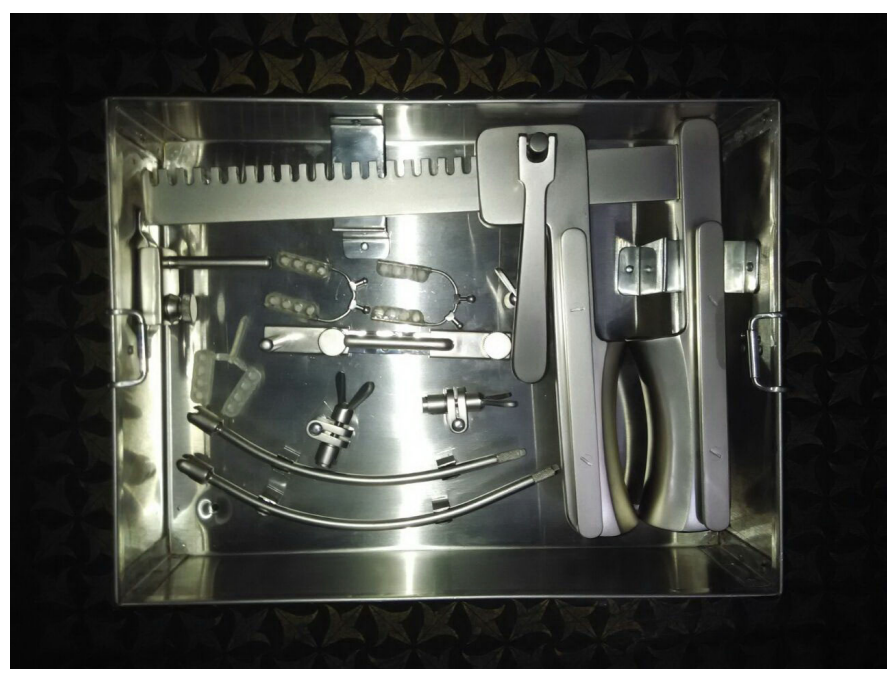

Photo 2. SIMS, a combo device.

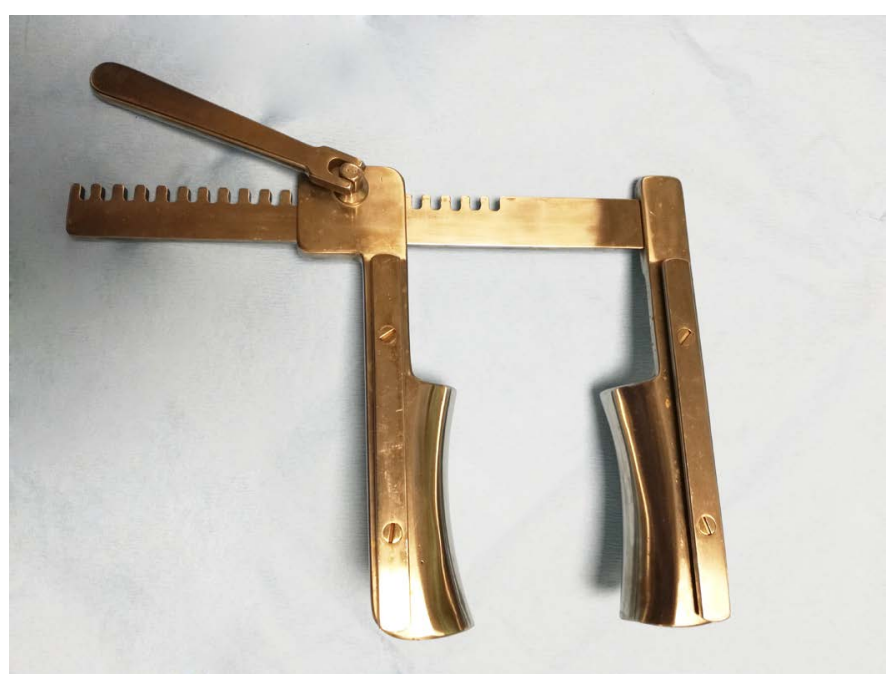

Photo 3. Sternal spreader with a railing on both sides. 


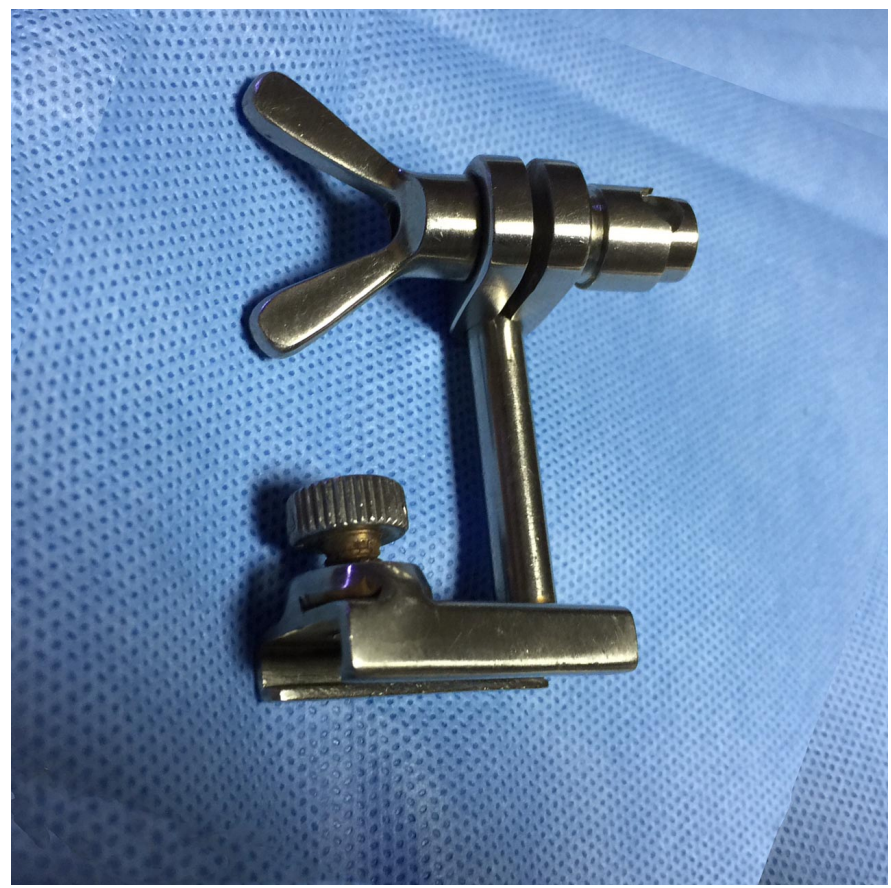

Photo 4. Vertical two inch metallic rod.

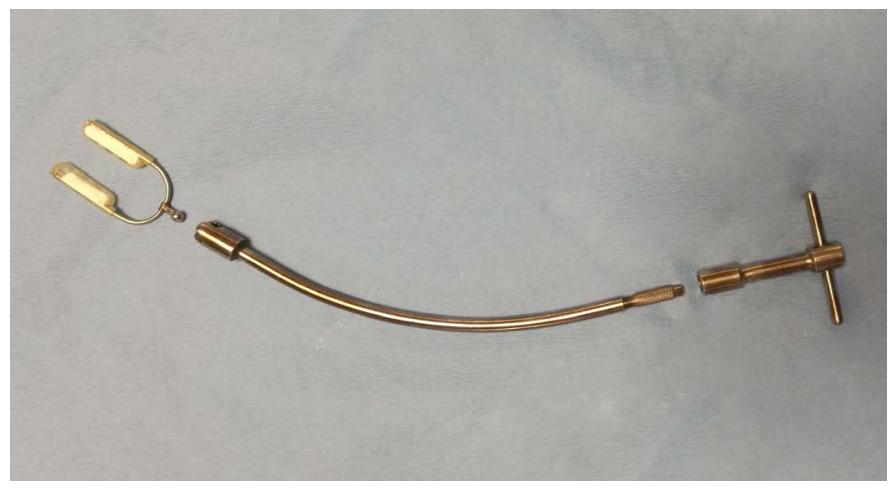

Photo 5. The stabilizer rod.

conventional stabilizers, which could be attached to the suction apparatus and used as suction stabilizer as well. Over time, once we get used to the stabilizer we can avoid the suction unless it is absolutely needed.

\section{Results}

When we compared the 600 patients who underwent OPCAB using our SIMS with an equal number of patients who had OPCAB done using Maquet stabilizer, we found that there were no significant difference in any of the clinical parameters we compared. In fact, we noticed that the male, female ratio were similar in both the groups. The target vessel grafted and the conduits used were also similar in both the groups. The only factor we noticed in the clinical data was that there was a significant number of patients who had IABP use in the Maquet group compared to the SIMS group. Though none of these patients had to be 
converted on to the heart lung machine. In fact we had published our last data on our OPCABs which showed that over the last ten years we have had no conversions on to the Cardio-pulmonary bypass so far [8].

\section{Discussion}

OPCAB surgery started in the early nineties after Buffalo (1985) and Benetti (1991) reported their individual papers on how they had been able to perform coronary bypass surgery without going on the heart lung machine [9] [10]. These publications stimulated our group to start performing OPCABs in all patients who had to undergo CABG. The Utrecht group published (1996) their seminal article after which the name Octopus became a name synonymous with beating heart surgery [11]. This was the first commercially available stabilizer that was available to perform OPCAB in all the coronary arteries around the heart. After that many disposable stabilizers came into the market and have remained so far. But the need to be able to reuse and recycle these stabilizers made us research for developing an indigenous reusable metallic stabilizer which could be used as any surgical steel instrument [12].

Development of this stabilizer actually brought down our carbon foot print significantly that the last 600 odd patients could undergo OPCAB with the same device and only the pods have been changed frequently. Hence apart from saving on cost incurred per patient, it has also improved our expertise to perform such surgeries. Hence with increasing expertise in OPCAB surgery, we hope that this type of instrumentation would be able to make inroads into developing this specialty and that after a decade on pump CABG would be a thing of the past.

We have also uploaded videos which how SIMS has been used by us in different positions of the heart in youtube. That can be seen on clicking this link or copy pasting this. The youtube link is

https://www.youtube.com/playlist?list=PLmvb6npEfabinhlatq8IYLBz8WlHo8bu1.

\section{Acknowledgements}

We would like to acknowledge the work done by Mr. Arun, who had diligently provided the data work and Mr Bipin, who, worked on the page setting and the photograph. Mr Gopalakrishnan of G\&S industries has been the man who made the first Prototype and now the final version on which the stabilizer is now ready for manufacturing. Would like to acknowledge him for his perseverance and hard work, without which this SIMS would not have materialized. Also acknowledging the input of Mr Saiju, our surgical asst. and Mr Jayaprakash, our chief perfusionist, who has spend time with us in developing this product.

\section{Conflicts of Interest}

The author declares no conflicts of interest regarding the publication of this paper. 


\section{References}

[1] Vettath, M.P. (2003) Vettath's Anastomotic Obturator: A Simple Proximal Anastomotic Device. The Heart Surgery Forum, 6.

[2] Vettath, M.P., Kannan, A.V., Sheen Peecheeyen, C.S., Baburajan, A.K., Vahab, A. and Sujith, M.P. (2004) Vettath's Anastomotic Obturator-Our Experience of 269 Proximal Anastamosis. Heart Lung and Circulation, 13, 288-290. https://doi.org/10.1016/j.hlc.2004.02.019

[3] Prabhu, A.D., Karim, R.A., Rajendran, S., Thazhkuni, I.E., Thamaran, R.A., Vellachami, K.A. and Vettath, M.P. (2008) Vettath's Technique of Long Mammary Patch Reconstruction of a Diffusely Diseased Left Anterior Descending Coronary Artery without Endarterectomy on the Beating Heart. The Heart Surgery Forum, 11, 64-67. https://doi.org/10.1532/HSF98.20071155

[4] Prabhu, A.D., Thazhkuni, I.E., Rajendran, S., Thamaran, R.A., Vellachamy, K.A. and Vettath, M.P. (2008) Mammary Patch Reconstruction of Left Anterior Descending Coronary Artery. Asian Cardiovascular and Thoracic Annals, 16, 313-317. https://doi.org/10.1177/021849230801600412

[5] Vettath, M.P., Ismail, E., Kannan, A. and Murali, A. (2012) Re-Engineering in OPCAB Surgery, Special Topics in Cardiac Surgery, Narin, C., Ed.

http://www.intechopen.com/articles/show/title/re-engineering-in-opcab-off-pumpcoronary-artery-bypass-surgery

[6] Vettath, M.P., Ismail, E. and Kannan, A. (2013) Re-Engineering in OPCAB-A Vettath's Perspective. World Journal of Cardiovascular Disease, 3, 33-44. https://doi.org/10.4236/wjcd.2013.34A006

[7] Vettath, M., et al. (2016) Role of Intra Aortic Balloon Pump in off Pump Coronary Artery Bypass-A Vettath Modification. World Journal of Cardiovascular Disease, 6, 188-195. https://doi.org/10.4236/wjcd.2016.66020

[8] Vettath, M.P., Ravisankar, M., Kopjar, T., Kannan, A.V. and Gangadharan, N. (2018) The Heart Su Off-Pump Coronary Artery Bypass Grafting Improves Early Clinical Outcomes Including Operative Mortality. The Heart Surgery Forum, 21. https://doi.org/10.1532/hsf.2007

[9] Buffolo, E., Andrade, J.C.S., Succi, J.E., et al. (1985) Direct Myocardial Revascularization without Cardiopulmonary Bypass. The Thoracic and Cardiovascular Surgeon, 33, 26-29. https://doi.org/10.1055/s-2007-1014076

[10] Benetti, F.J., Naselli, C., Wood, M. and Geffner, L. (1991) Direct Myocardial Revascularization without Extracorporeal Circulation. Experience in 700 Patients. Chest, 100, 312-316. https://doi.org/10.1378/chest.100.2.312

[11] Borst, C., Jansen, E.W., Tulleken, C.A., et al. (1996) Coronary Artery Bypass Grafting without Cardiopulmonary Bypass and without Interruption of Native Coronary Flow Using a Novel Anastomosis Site Restraining Device (“Octopus”). Journal of the American College of Cardiology, 27, 1356-1364. https://doi.org/10.1016/0735-1097(96)00039-3

[12] Vettath, M.P. (2017) Reuse, Recycle and Reduce in OPCAB. Austin Cardiology, 2, 1014. https://doi.org/10.26420/austincardiol.2017.1014 